University of Nebraska - Lincoln

DigitalCommons@University of Nebraska - Lincoln

7-17-2006

\title{
Polyvinylidene fluoride-trifluoroethylene as a reservoir for absorbed water
}

\author{
P.A. Jacobson \\ University of Nebraska-Lincoln \\ Luis G. Rosa \\ University of Nebraska-Lincoln, luis.rosa13@upr.edu \\ Kristin Kraemer \\ University of Nebraska-Lincoln, kkraemer2@unl.edu \\ Stephen Ducharme \\ University of Nebraska, sducharme1@unl.edu \\ Peter A. Dowben \\ University of Nebraska-Lincoln, pdowben@unl.edu
}

Follow this and additional works at: https://digitalcommons.unl.edu/physicsdowben

Part of the Physics Commons

Jacobson, P.A.; Rosa, Luis G.; Kraemer, Kristin; Ducharme, Stephen; and Dowben, Peter A., "Polyvinylidene fluoride-trifluoroethylene as a reservoir for absorbed water" (2006). Peter Dowben Publications. 116.

https://digitalcommons.unl.edu/physicsdowben/116

This Article is brought to you for free and open access by the Research Papers in Physics and Astronomy at DigitalCommons@University of Nebraska - Lincoln. It has been accepted for inclusion in Peter Dowben Publications by an authorized administrator of DigitalCommons@University of Nebraska - Lincoln. 


\title{
Polyvinylidene fluoride-trifluoroethylene as a reservoir for absorbed water
}

\author{
P. A. Jacobson, Luis G. Rosa, Kristin Kraemer, Stephen Ducharme, P. A. Dowben* \\ Department of Physics and Astronomy and the Nebraska Center for Materials and Nanoscience, \\ Behlen Laboratory of Physics, University of Nebraska-Lincoln, Nebraska 68588-0111
}

Submitted May 2006; accepted June 23, 2006; published online July 17, 2006

\begin{abstract}
The absorption of water in Langmuir-Blodgett films of ferroelectric copolymers of polyvinylidene fluoride with trifluoroethylene is shown to depend upon the film thickness. This water absorption can have a profound effect on the dielectric properties of the copolymer films.
\end{abstract}

Keywords: Crystalline polymers, Water absorption, Ferroelectric capacitance

Low production cost capacitors with very high energy densities could well revolutionize portable power. Ferroelectric copolymers of polyvinylidene fluoride with trifluoroethylene have achieved record energy densities of $400 \mathrm{~J}$ per cubic centimeter [1]. While the energy density of a capacitor goes as the dielectric constant divided by the square of the thickness, clearly changes in the dielectric properties will affect the properties of the capacitor. Water absorption does alter the dielectric properties of the ferroelectric copolymers of polyvinylidene fluoride with trifluoroethylene [2].

Water is ubiquitous in nature and, among small molecules, has a relatively large electric dipole moment. This water dipole moment contributes to the complexity of water interaction with surfaces (and polymers). Water absorption is also known to change the dielectric properties of polymers, including the ferroelectric copolymers of polyvinylidene fluoride with trifluoroethylene, $\mathrm{P}(\mathrm{VDF}-\mathrm{TrFE})$ [2-4]. An interaction between the dipole of water and the dipole of the ferroelectric [5-10] copolymers of polyvinylidene fluoride has been suggested. In spite of the complexities of polymer surface characterization, water has nevertheless been identified as a cause of molecular reorientation at polymer surfaces [11-22], including the surface structure of fluorinated polymers $[5,23,24]$.

Copolymer films of $\mathrm{P}(\mathrm{VDF}-\mathrm{TrFE})$ family have proved to be an opportune platform for studying the interactions between wa- ter and organic polymers $[2-10,25]$, in particular organic polymers with strong electric dipole moment, partly because of the high crystallinity of the films formed by Langmuir-Blodgett monolayer deposition from water subphase. Poly(vinylidene fluoride) [PVDF, $-\left(\mathrm{CH}_{2}-\mathrm{CF}_{2}\right)_{\mathrm{n}}-$ ] copolymers with trifluoroethylene [TrFE, $\left.-\left(\mathrm{CHF}-\mathrm{CF}_{2}\right)-\right]$ can form highly ordered crystalline ferroelectric ultrathin films as has been demonstrated by X-ray and neutron scattering [2, 26-29], scanning tunneling microscopy $[26,30-33]$, low energy electron diffraction $[26,33]$ and band mapping $[26,33]$. $\mathrm{P}(\mathrm{VDF}-\mathrm{TrFE} 70: 30)$ is relatively simple to prepare, it does not significantly react or degrade with time, and most importantly the surface is highly reproducible.

It is now increasingly apparent that the polymer surface does play a key role in water absorption $[2,5,25]$ and desorption $[2$, $7,25]$, but structural studies [2,25] and dielectric measurements $[2-4,8,10]$ suggest that the entire volume may absorb some water. Water, as an absorbate in P(VDF-TrFE 70:30), should have a significant effect on the dielectric properties of this polymer dielectric $[2-4,8-10]$, if the water content is sufficiently large. The goal of this work is to characterize the water absorption and demonstrate that the extent of water absorption depends on both temperature and the volume of $\mathrm{P}(\mathrm{VDF}-\mathrm{TrFE}$ 70:30). As shown here and elsewhere [2], the absorption of water clearly affects the dielectric properties of $\mathrm{P}(\mathrm{VDF}-\mathrm{TrFE}$ 70:30), and suggests a role for strong dipole interactions between water and this ferroelec-

\footnotetext{
* Corresponding author: E-mail pdowben@unl.edu (P.A. Dowben)
} 
tric polymer [2-5, 8-10]. The orientation for absorbed water may significantly differ from the orientation adopted by adsorbed water [5], though dipole interactions at the surface of $\mathrm{P}(\mathrm{VDF}-\mathrm{TrFE}$ 70:30) are certainly indicated by the fact that a commensurate hexagonal ice layer can be grown at the surface of $\mathrm{P}(\mathrm{VDF}-\mathrm{TrFE}$ 70:30), nucleated by the polymer surface dipoles [6].

Thin films of $70 \%$ vinylidene fluoride with $30 \%$ trifluoroethylene, P(VDF-TrFE 70:30), were prepared by LangmuirBlodgett (LB) deposition from a water subphase. This method can produce films as thin as 1 monolayer $[27,32]$. The films used for desorption studies were grown on highly ordered pyrolytic graphite (HOPG) and the P(VDF-TrFE 70:30) film thicknesses ranged from 3 to $35 \mathrm{ML}$ thick (5.4 nm-63 nm [34]).

Thermal desorption spectra were recorded with a quadrupole mass spectrometer (Dycor) in an ultrahigh vacuum (UHV) chamber as described elsewhere $[2,5,7,25]$. The graphite substrate supporting the $\mathrm{P}(\mathrm{VDF}-\mathrm{TrFE}$ 70:30) was held between tantalum mounts and heated resistively at a rate of $0.5 \mathrm{~K} / \mathrm{s}$. This slow heating rate was used to minimize the effect of thermal gradients in the sample and sample holder. Prior to absorption and desorption experiments the thin film was annealed in vacuum at $370 \mathrm{~K}$, which has been shown to leave the films with a surface free from impurities (including water) [35]. For the experiments undertaken here, water vapor was exposed to the thin films of P(VDFTrFE 70:30) at $120 \mathrm{~K}$. After exposure of the sample to water, the chamber was further evacuated for five minutes to reduce the water partial pressure, to $10^{-9}$ Torr or less unless noted otherwise.

Films used for capacitance measurements consisted of $30 \mathrm{ML}$ of P(VDF-TrFE 70:30) also made by the LB technique, deposited onto a glass substrate with aluminum strip electrodes $500 \mathrm{~nm}$ thick and $1 \mathrm{~mm}$ wide. The samples were then annealed at 400 $\mathrm{K}$ for $1 \mathrm{~h}$ to improve crystallinity. Additional details on sample preparation were previously reported [2]. Leads for electrical measurements were soldered to the ends of the electrode strip with indium.

For the capacitance experiments, both the humidity and temperature were controlled while the capacitance was measured. The sample was placed into a copper chamber that could be maintained at constant temperature and humidity. The temperature was controlled to within $\pm 1 \mathrm{~K}$ by proportional feedback using a platinum temperature sensor and both resistive heaters and thermoelectric coolers. The humidity was controlled to within $\pm 5 \%$ relative humidity $(\mathrm{RH})$ by proportional feedback using a polymer humidity sensor (HYCAL Sensing Products, Model HIH-3206-C) and a proportioning valve system to mix saturated water vapor in warm air with bottled nitrogen. The total gas flow through the chamber was kept constant at $3 \mathrm{~L} / \mathrm{min}$ while adjusting independent valves on the water vapor and nitrogen lines to maintain the chamber humidity. Each measurement was made at a fixed temperature and starting humidity, for example, $40{ }^{\circ} \mathrm{C}$ and $60 \% \mathrm{RH}$, as follows. The sample chamber was first baked dry for $20 \mathrm{~min}$ at $80{ }^{\circ} \mathrm{C}$ with a pure nitrogen flush. The sample was cooled to the desired temperature and then the humidity set point increased to the desired value, and allowed to soak for one hour. At the end of the one-hour soak, the chamber was flushed with dry nitrogen gas, at the flow rate of $3 \mathrm{~L} / \mathrm{min}$ while recording the sample capacitance, the chamber humidity and temperature.
Following exposure of water to crystalline thin films of $\mathrm{P}(\mathrm{VDF}-\mathrm{TrFE})$ at $120-135 \mathrm{~K}$, the thermal desorption spectra are characterized by two desorption peaks, as indicated in Fig. 1, and reported elsewhere $[2,5-7,25]$. The thermal desorption of water at $150-160 \mathrm{~K}$ is characteristic of water sublimation or the thermal desorption of ice from relatively inert substrates [36- 40]. This particular adsorption species does not saturate with increasing water exposure, but continues to increase in intensity. We associate this water species with the formation of surface "ice" or similar species, as has been done in similar thermal desorption studies of water ice $[2,5-7,25,36-40]$. It is important to note that the formation of this ice-like species is not observed with small exposures of water to the $\mathrm{P}(\mathrm{VDF}-\mathrm{TrFE})$ thin film samples cooled to 120-130 K [2, 5-7, 25].

For small exposures of water, 4-8 L ( $1 \mathrm{~L}=1 \times 10^{-6}$ Torr s), to $\mathrm{P}(\mathrm{VDF}-\mathrm{TrFE})$ at $120-130 \mathrm{~K}$, the water thermal desorption spectra from a nominally 3-4 monolayer film show only one broad feature centered around $280-300 \mathrm{~K}$. With increasing exposure to water, this broad feature, in the thermal desorption spectra, increases in intensity but with sufficient exposure to water at 120

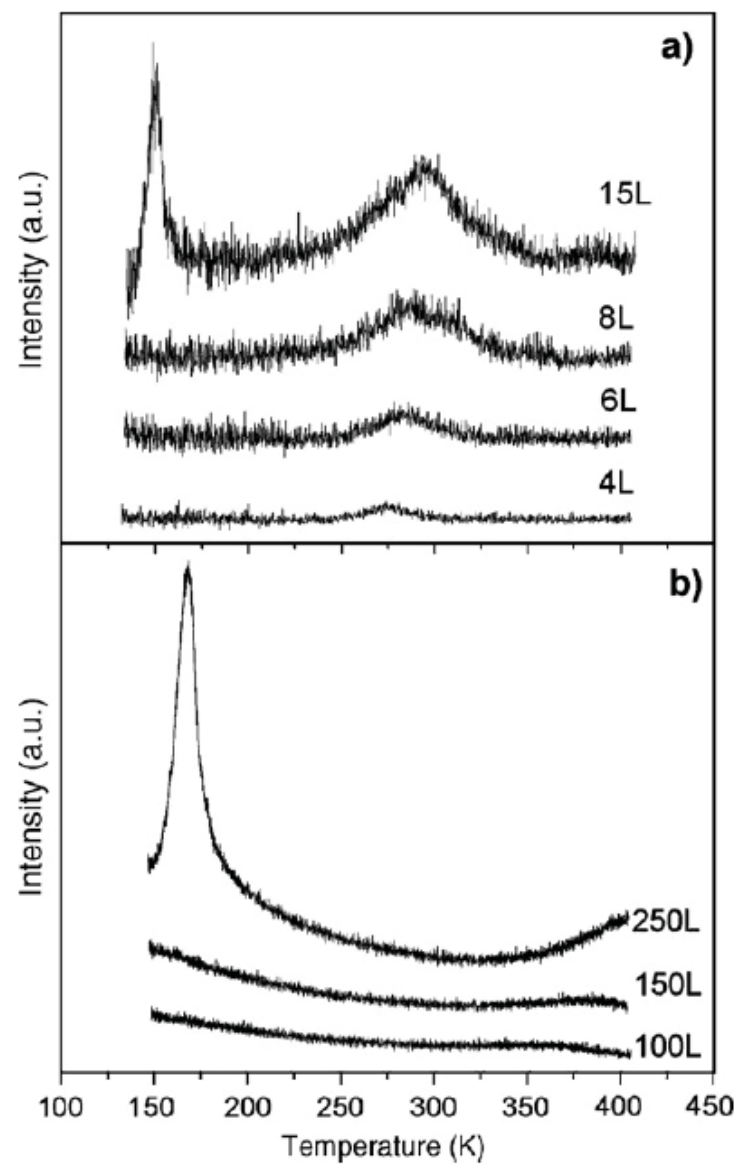

Fig. 1. Coverage dependent thermal desorption from a) $3 \mathrm{ML}$ and b) $35 \mathrm{ML}$ thick $\mathrm{P}(\mathrm{VDF}-\mathrm{TrFE}, 70: 30)$ samples cooled to $125 \mathrm{~K}$, and then exposed to water vapor. The broad peak at $280-300 \mathrm{~K}$ is the signature of the desorption of absorbed water, while the sharp peak at $150-160 \mathrm{~K}$ is surface ice, indicating that surface ice formation at roughly $15 \mathrm{~L}$ and $250 \mathrm{~L}$ on the $3 \mathrm{ML}$ and $35 \mathrm{ML}$ thick $\mathrm{P}(\mathrm{VDF}-\mathrm{TrFE}$, 70:30) samples respectively. 


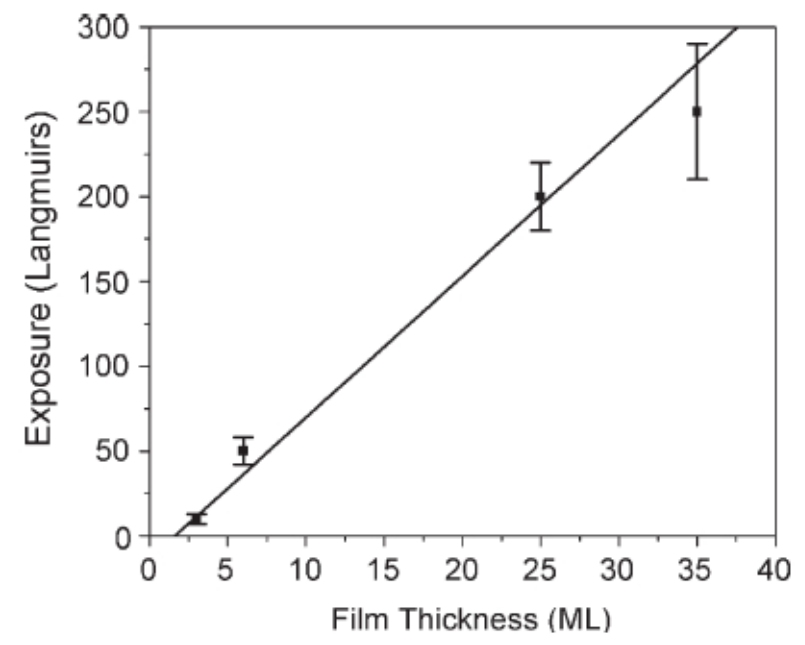

Fig. 2. The extent of water exposure to $P(V D F-T r F E, 70: 30)$ required for the formation of water ice as a function of $\mathrm{P}(\mathrm{VDF}-\mathrm{TrFE})$ film thickness. The solid line is the best fit to the data.

$130 \mathrm{~K}$, there is also desorption of water from the $\mathrm{P}(\mathrm{VDF}-\mathrm{TrFE})$ centered at $150-160 \mathrm{~K}$. This water exposure dependent behavior in the thermal desorption spectra is shown in Fig. 1 for a nominally 3 monolayer film and a 35 monolayer film of P(VDF-TrFE 70:30).

Using the thermal desorption feature observed in the range 150 $\mathrm{K}-160 \mathrm{~K}$ as characteristic of the formation of ice, we can make some assessment of how much water exposure is required for ice formation on $\mathrm{P}(\mathrm{VDF}-\mathrm{TrFE})$ at $120-130 \mathrm{~K}$. We find that there is a roughly linear relationship between the film thickness and the exposure required for surface ice formation, as summarized in Fig. 2 . This suggests that the thicker the $P(V D F-T r F E)$ film, the more water must be absorbed prior to the formation of a surface water ice. Of course this implies that water is absorbed in P(VDFTrFE) at $120-130 \mathrm{~K}$, as has been previously suggested $[2,5-7$, 25].

The absorption of water by $\mathrm{P}(\mathrm{VDF}-\mathrm{TrFE})$ at $120 \mathrm{~K}$ is also matched by the egress of absorbed water at the same temperature. The sublimation of water, if not affected by the absorbed water, should obey a simple exponential decay function as a process de-

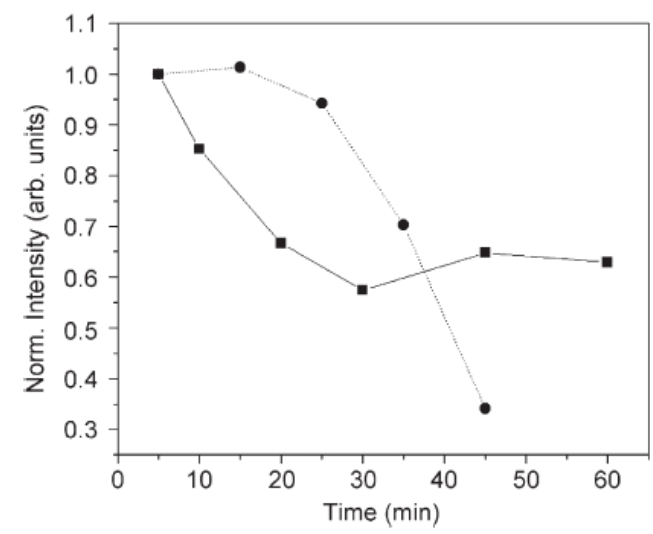

Fig. 3. Relative intensity of the $\mathrm{P}(\mathrm{VDF}-\mathrm{TrFE} 70: 30)$ desorption peak at $150 \mathrm{~K}$ with respect to time after adsorption at $120 \mathrm{~K}, 3 \mathrm{ML}(\mathbf{\square})$ and $25 \mathrm{ML}(\bullet)$, respectively.

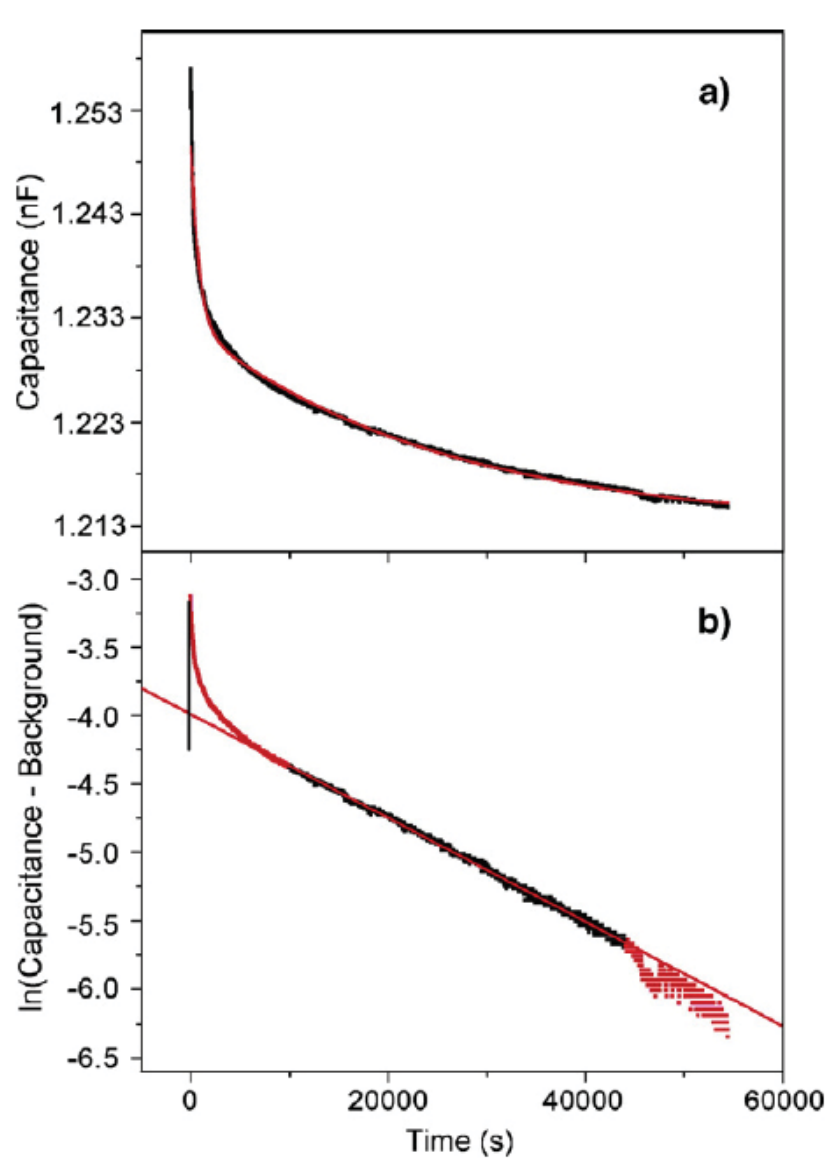

Fig. 4. The dependence of capacitance on time during dry nitrogen flush for capacitance samples prepared at initial conditions $40{ }^{\circ} \mathrm{C}$ and $60 \%$ relative humidity (RH). a) A linear plot showing the exponential decay of a $30 \mathrm{ML}$ thick P(VDF-TrFE) sample capacitance (black curve) and double exponential fitting (red curve). b) A plot of the natural logarithm of the capacitance, along with a linear fit to the data between $10,000 \mathrm{~s}$ and $44,000 \mathrm{~s}$, used to determine the second exponential decay time constant of $1.3 \pm 0.3 \times 10^{3} \mathrm{~s}$.

pendent of the activation barrier for sublimation alone. This can be probed by undertaking thermal desorption with increasing delay times between water exposure to the P(VDF-TrFE) sample at $120 \mathrm{~K}$ and the onset of annealing. The expected sublimation behavior is generally obeyed for the thinner $\mathrm{P}(\mathrm{VDF}-\mathrm{TrFE})$ films, but is not the case for thicker P(VDF-TrFE) films. When the time between water exposure and the thermal desorption measurements is extended, we see a decrease in thermal desorption signal intensities, associated with the surface ice (150-160 K), that deviates considerably from a simple Arrhenius behavior for the 25 monolayer P (VDF-TrFE) films, as seen in Fig. 3.

The competition between water ice sublimation and the diffusion of water in and out of $\mathrm{P}(\mathrm{VDF}-\mathrm{TrFE})$ is expected based on the low barriers to bulk water diffusion in $\mathrm{P}(\mathrm{VDF}-\mathrm{TrFE})$. Indeed as noted elsewhere [5], the migration of water, even at temperatures as low as $100 \mathrm{~K}$, is quite facile in molecular dynamics simulations of absorbed water in $\mathrm{P}(\mathrm{VDF}-\mathrm{TrFE})$ films. As seen in Fig. 3 , the absorbed water can provide a reservoir for the formation of surface ice, even after most of the surface ice is expected to have sublimed. 
The interplay between sublimation and diffusion is different for thick and thin films of $\mathrm{P}(\mathrm{VDF}-\mathrm{TrFE} 70: 30)$. For a 3 monolayer $\mathrm{P}(\mathrm{VDF}-\mathrm{TrFE})$ film, the thermal desorption rate from an ice layer on $\mathrm{P}(\mathrm{VDF}-\mathrm{TrFE})$ decreases rapidly initially, then remains roughly constant at $60 \%$ of original thermal desorption peak intensity for ice for increasing delay times (between exposure and the onset of annealing) up to $60 \mathrm{~min}$ in UHV, after water exposure to P(VDFTrFE) at $120-130 \mathrm{~K}$. For the $25 \mathrm{ML}$ thick film of P(VDF-TrFE), far more water is absorbed, thus the desorption signal associated with the surface water ice decreases rapidly only after delay times of $25 \mathrm{~min}$ (between exposure and the onset of annealing). For the thicker P(VDF- TrFE) films, the ice layer appears to be maintained by egress of absorbed water to the surface, effectively contributing to the volume of ice, for delay times of up to $20 \mathrm{~min}$ (Fig. 3). The rapid decreases to $35 \%$ of the original peak intensity within $45 \mathrm{~min}$, however suggest that there are two rate constants that dominate the diffusion of bulk absorbed water to the surface. There is also evidence for two rate constants governing absorbed water desorption in the capacitance measurements.

Thermal desorption studies, like many surface science studies carried out under ultrahigh vacuum conditions (i.e. in the region of $10^{-10}$ Torr), are often difficult to relate to measurements that apply more to the "realistic environments" in which the actual materials are used. In the case of P(VDF-TrFE 70:30), the working environments will likely have far higher partial pressures for water (humidity) than seen under the vacuum conditions just described, resulting in far higher levels of water absorption. This suggests that water absorption can play a significant role in altering the dielectric properties of $\mathrm{P}(\mathrm{VDF}-\mathrm{TrFE} 70: 30)$, since water loss through sublimation, seen with good vacuum conditions, will be suppressed by the constant background partial pressure of water vapor. Capacitance measurements, carried out in the presence of ambient water vapor, provide ample evidence that this is indeed the case.

The measurements of the P(VDF-TrFE) film capacitance, following absorption of water from the ambient water vapor, show a decrease in the film capacitance associated with a decrease in the amount of absorbed water when the sample chamber was flushed with nitrogen. The P(VDF-TrFE) film capacitance decreased with an approximately exponential dependence on time, as shown in Fig. 4. The capacitance curves appear to have two time constants associated with the loss of absorbed water, but with no strong dependence on temperature over the range from $15{ }^{\circ} \mathrm{C}$ to $80^{\circ} \mathrm{C}$. The absence of a significant temperature dependence over this range does suggest that the bulk ferroelectric phase transition for $\mathrm{P}(\mathrm{VDF}-\mathrm{TrFE} 70: 30)$, which occurs at $80^{\circ} \mathrm{C}$, does not play a significant role in the changing capacitance.

The short time constant is related to the flush rate of the chamber and the drying conditions, suggesting that the surface and interface regions absorb water $[9,10]$ that is also readily desorbed. The longer time constant is related to the absorbed water leaving the bulk of the film. The average time constant for water desorption into an ambient dry nitrogen atmosphere was $1.3 \pm 0.3 \times 10^{3}$ $\mathrm{s}$, preceded by short time constant for the desorption of absorbed water whose average was $0.56 \pm 0.18 \times 10^{3} \mathrm{~s}$. The longer time constant was found two ways - by fitting the exponential data itself with a 2-exponential nonlinear regression and by taking the $\log$ of the data and then fitting the linear part of the data (see Fig. $4 \mathrm{~b}$ ). In both types of fit, the background capacitance was sub- tracted before making the fit. Both these measurements and thermal desorption measurements suggest that water desorption is a competition between water desorption from the surface and near surface region and diffusion and migration of absorbed water to the surface and near surface region of $\mathrm{P}(\mathrm{VDF}-\mathrm{TrFE})$.

In summary, we find that water is absorbed within P(VDFTrFE) Langmuir-Blodget films and that the extent of water absorption scales linearly with film thickness. Thermal desorption shows that the $\mathrm{P}(\mathrm{VDF}-\mathrm{TrFE}$ 70:30) films can retain some absorbed water for more than an hour in UHV, after adsorption at $125 \mathrm{~K}$, even at low background partial pressures. There is evidence for diffusion of absorbed water to the surface, from the bulk of the P(VDF-TrFE 70:30) films, though this process depends on film thickness. P(VDF-TrFE 70:30) films that are exposed to water show a decrease in capacitance related to a decrease in absorbed water, and this loss of absorbed water is dominated by two time constants.

\section{Acknowledgements}

This work was supported by the National Science Foundation through grant CHE-0415421 and the NSF "QSPINS" MRSEC (DMR 0213808). We thank A.V. Sorokin, C.M. Othon and V.M. Fridkin for their advice and assistance with the capacitance experiments.

\section{References}

[1] S. Ducharme,S.P. Palto,L.M.Blinov, V.M. Fridkin, AIPConference Proceedings "Conference on the Fundamental Physics of Ferroelectrics", 2000.

[2] P.A. Jacobson, L.G. Rosa, C.M. Othon, K.L. Kraemer, A.V. Sorokin, S. Ducharme, P.A. Dowben, Appl. Phys. Lett. 84 (2004) 88.

[3] A.S. Castela, A.M. Simoes, Corros. Sci. 45 (2003) 1631.

[4] A.S. Castela, A.M. Simoes, Corros. Sci. 45 (2002) 1647.

[5] L.G. Rosa, I.N. Yakovkin, P.A. Dowben, J. Phys. Chem., B 109 (2005) 14189.

[6] L.G. Rosa, Jie Xiao, Yaroslav B. Losovyj, Yi Gao, I.N. Yakovkin, Xiao C. Zeng, Peter A. Dowben, J. Am. Chem. Soc. 127 (2005) 17261.

[7] L.G. Rosa, P.A. Jacobson, P.A. Dowben, J. Phys. Chem., B 110 (2006) 7944-7950.

[8] N.L. Levshin, S.G. Yudin, A.P. Diankina, Moscow Univ. Phys. Bull. 52 (1997) 71-74.

[9] N.L. Levshin, S.G. Yudin, Moscow Univ. Phys. Bull. 54 (1999) 34-38.

[10] N.L.Levshin, S.G. Yudin, Vysokomol. Soedin., Ser. B. 46 (2004) 1981-1984; (English edition), Polym. Sci., Ser. B 46 (2004) 11-12.

[11] X. Chen, J.A. Gardella, T. Ho, K.J. Wynne, Macromolecules 28 (1995) 1635.

[12] M. Toselli, M. Messori, R. Bongiovanni, G. Malucelli, A. Priola, F. Pilati, C. Tonelli, Polymer 42 (2001) 1771.

[13] J.X. Chen, H.Z. Zhuang, J. Zhao, J.A. Gardella, Surf. Interface Anal. 31 (2001) 713. 
[14] J.A. Gardella, C.M. Mahoney, Appl. Surf. Sci. 231/2 (2004) 283.

[15] M. Toselli, J.A. Gardella, M. Messori, A.M. Hawkridge, F. Pilati, C. Tonelli, Polymer Int. 52 (2003) 1262.

[16] A. Opdahl, R.A. Phillips, G.A. Somorjai, J. Polym. Sci., Part B, Polym. Phys. 42 (2004) 421.

[17] K.B. Lewis, B.D. Ratner, J. Colloid Interface Sci. 159 (1993) 77.

[18] T. Yasuda, M. Miyyama, H. Yasuda, Langmuir 10 (1994) 583.

[19] A.M. Hawkridge, J.A. Gardella, M. Toselli, Macromolecules 35 (2002) 6533.

[20] S.H. Lee, E.J. Ruckenstein, J. Colloid Interface Sci. 120 (1987) 529.

[21] J. Lukás, R.N.S. Sodhi, M.V. Sefton, J. Colloid Interface Sci. 174 (1995) 421.

[22] H. Yasuda, T. Okuno, Y. Sawa, T. Yasuda, Langmuir 11 (1995) 3255.

[23] E. Ruckenstein, S.V. Gourisankar, J. Colloid Interface Sci. 107 (1985) 488

[24] E. Ruckenstein, S.V. Gourisankar, J. Colloid Interface Sci. 109 (1986) 557.

[25] L.G. Rosa, P.A. Jacobson, P.A. Dowben, J. Phys. Chem., B 109 (2005) 532-535.

[26] J. Choi, C.N. Borca, P.A. Dowben, A.V. Bune, M. Poulsen, S. Pebley, S. Adenwalla, S. Ducharme, L. Robertson, V.M. Fridkin, S.P. Palto, N. Petukhova, S.P. Yudin, Phys. Rev., B $61(2000) 5760$.

[27] L.M. Blinov, V.M. Fridkin, S.P. Palto, A.V. Bune, P.A. Dowben, S. Ducharme, Usp. Fiz. Nauk 170 (2000) 247; (Engl. Transl.), Phys. Uspekhi 43 (2000) 243.

[28] C.N. Borca, S. Adenwalla, J. Choi, P.T. Sprunger, S. Ducharme, L. Robertson, S.P. Palto, J. Liu, M. Poulsen, V.M. Fridkin, H. You, P.A. Dowben, Phys. Rev. Lett. 83 (1999) 4562.
[29] C.N. Borca, J. Choi, S. Adenwalla, S. Ducharme, P.A. Dowben, L. Robertson,

V.M. Fridkin, S.P. Palto, N. Petukhova, Appl. Phys. Lett. 74 (1999) 347.

[30] H. Qu, W. Yao, T. Garcia, J. Zhang, S. Ducharme, P.A. Dowben, A.V. Sorokin, V.M. Fridkin, Appl. Phys. Lett. 82 (2003) 4322 .

[31] L. Cai, H. Qu, C. Lu, S. Ducharme, P.A. Dowben, J. Zhang, Phys. Rev., B 70 (2004) 155411.

[32] A.V. Bune, V.M. Fridkin, S. Ducharme, L.M. Blinov, S.P. Palto, A.V. Sorokin, S.G. Yudin, A. Zlatkin, Nature 391 (1998) 874.

[33] J. Choi, P.A. Dowben, S. Ducharme, V.M. Fridkin, S.G. Palto, N. Pethukova, S.G. Yudin, Phys. Lett., A 249 (1998) 505 .

[34] M.J. Bai, A.V. Sorokin, D.W. Thompson, M. Poulsen, S. Ducharme, C.M. Herzinger, S.P. Palto, V.M. Fridkin, S.G. Yudin, V.E. Savchenko, L.K. Gribova, J. Appl. Phys. 95 (2004) 3372-3377.

[35] J. Choi, E. Morikawa, S. Ducharme, P.A. Dowben, Matt. Lett. 59 (2005) 3599-3603.

[36] D. Charkarov, B. Kasemo, Phys. Rev. Lett. 81 (1998) 5181.

[37] D.V. Charkarov, L. Ǿsterlund, B. Kasemo, Langmuir 11 (1995) 1201.

[38] T. Sueyoshi, T. Sasaki, Y. Iwasawa, J. Phys. Chem., B 101 (1997) 4648.

[39] J. Dvorak, H.-L. Dai, J. Chem. Phys. 112 (2000) 923.

[40] G.A. Kimmel, N.G. Petrik, Z. Dohnálek, B.D. Kay, Phys. Rev. Lett. 95 (2005) 166102. 